\title{
Staminate Flower of Cocos Nucifera as Green Inhibitor for Mild Steel in HCl Medium
}

\author{
R. RAJALAKSHMI ${ }^{1}$ AND A. S. SAFINA ${ }^{2}$ \\ ${ }^{1}$ Department of Chemistry \\ Avinashilingam University for Women, Coimbatore, India \\ ${ }^{2}$ Department of Chemistry \\ V.L.B.Janakiammal College of Engg. \& Tech, Coimbatore, India \\ raji_adu@yahoo.com \\ rajivardhan@gmail.com
}

Received 23 July 2011; Accepted 22 September 2011

\begin{abstract}
Corrosion control methods, especially the use of inhibitors, have gained monumental importance in the present scenario of expunging corrosion and the quest for eco-friendly reasons continues. To arrive at an inexpensive non-toxic, eco-friendly inhibitor formulations the present study on the use of Staminate Flower extract of Cocos Nucifera has been carried out by the classical weight loss measurements and electrochemical polarization measurements. The acid extract could bring out a maximum of $97.3 \%$ inhibition of mild steel corrosion in $1 \mathrm{M} \mathrm{HCl}$. Thermodynamic parameters of the corrosion process were calculated from temperature study. The adsorptive behaviour of Staminate Flower extract in acid solution may be approximated both by Langmuir and Temkin type isotherms. The results obtained by Tafel, Linear polarization resistance, and impedance spectroscopy have been correlated with the classical weight loss measurements. Values of Tafel constant ba and bc confirmed that the Staminate Flower extract acts like mixed type inhibitor. Examination of the surface of the metal in the presence of the inhibitor confirmed the deposition of inhibitor on the metal surface. The Staminate Flower extract in $\mathrm{HCl}$ medium efficiently inhibits the corrosion and proved to be zero cost inhibitor, eco-friendly, non-toxic, and highly economical.
\end{abstract}

Keywords: Corrosion, Inhibition, Mild steel, Staminate Flower.

\section{Introduction}

Mineral acids of various concentrations are extensively employed in various industrial processes including chemical cleaning, acid pickling, and acid descaling as well as in oil well acidification which result in corrosion. The environmental consequence of corrosion is enormous and its inhibition has been deeply investigated by several researchers. It has been found that one of the best methods of protecting metals against corrosion involves the use of inhibitors which are substances that slow down the rate of corrosion. 
The exploration of natural products of plant origin as inexpensive eco-friendly corrosion inhibitors is an essential field of study. In addition to being environmentally friendly and ecologically acceptable, plant products are cheap, readily available, and are renewable sources of materials ${ }^{1}$. The extracts from their leaves, barks, seeds, fruits, and roots comprise mixtures of organic compounds containing nitrogen, sulphur, and oxygen atoms and some $e^{2-6}$ have been reported to function as effective inhibitors of metal corrosion in different aggressive environments. Recent literature has shown that plant materials, such as Opuntia extract $^{7}$, Telferia occidentalis extract ${ }^{8}$, limonene ${ }^{9}$, Prosopis cineraria ${ }^{10}$, zallouh root $^{11}$, olives leaves $^{12}$, Datura stramonium ${ }^{13}$, Gossipium hirsutum extract ${ }^{14}$, Figus virens plant ${ }^{15}$, Datura metel $^{16}$, Allium sativum ${ }^{17}$, Zenthoxylum alatum ${ }^{18}$, juice extracts of Magnifera indica (mango) ${ }^{19}$, acidic extracts of Phyllantus amarus extract ${ }^{20}$ is effective inhibitor for metal in aggressive solutions.

Our research group investigated many plant extract ${ }^{21-32}$ which could furnish enhanced inhibition efficiency due to synergistic effect of phytochemical constituent present in the plant extract.

The aim of this present work is to study the inhibition potential of agricultural waste of coconut - staminate flower for mild steel in hydrochloric acid medium using weight loss and electrochemical measurements. Kinetic and thermodynamic parameters were evaluated from temperature studies. Optical electron microscope and FTIR techniques were carried to analyze the surface of mild steel in the presence of studied inhibitor.

\section{Experimental}

Corrosion tests were performed on a mild steel of the following percentage composition: $\mathrm{C}$ : 0.132, Mn: 0.23, Si: 0.021, P: 0.034, S: 0.031, Cr: 0.031, Mo: 0.016, Ni: 0.015, and remaining Fe. The metal was cut into pieces of area $5 \times 1 \mathrm{~cm}^{2}$. The specimens were polished mechanically, degreased, cleaned successively in deionized water, dried, stored in a desiccators, and used for all studies.

The plant materials used for the study were collected from the nearby residential area. $25 \mathrm{~g}$ of the Staminate flower was used as such. The extract was prepared by refluxing the flower in $500 \mathrm{~mL}$ of hydrochloric acid for $3 \mathrm{~h}$, kept overnight and filtered to get $5 \%$ extract.

\section{Phytochemical Constituents Present in SFCN Extract}

The coconut flower extract was found to be containing the following ${ }^{33}$ :

1. Steroids: a) Progesterone b) Hydroxy progesterone caproate

2. Cations: a) Sodium b) Ammonium c) Magnesium d) Calcium e) Iron f) Zinc

3. Anions: a) Chloride b) Phosphate c) Sulphate

4. Acetate: a) Lauric Acid b) Capric Acid c) Vitamin B6

\section{Weight Loss Method}

The polished and pre weighed MS specimens of uniform size in triplicate were suspended in $100 \mathrm{~mL}$ of electrolyte with and without the inhibitor at different concentrations for various periods of immersion at room temperature and at different temperatures. Then the specimens were washed, dried, and weighed. The weight loss was calculated. From this data, inhibition efficiency (IE) was calculated from the following equation:

$$
\text { Inhibition efficiency }=\frac{\text { Weight loss without inhibitor }- \text { Weight loss with inhibitor x } 100}{\text { Weight loss without inhibitor }}
$$


The weight loss method was also used to evaluate the performance of the inhibitor under study. It was determined for a period of 10 weeks. A part of the extract was kept at room temperature and the other portion was maintained in refrigerated condition. The same procedure as described for weight loss measurement was followed for an immersion period of $3 \mathrm{~h}$.

\section{Electrochemical Measurements}

A three electrode cell assembly consisting of a mild steel coupon embedded in specimen holder as working electrode, a large area Platinum mesh of negligible impedance as counter electrode and a saturated calomel electrode as reference electrode (RE) containing $100 \mathrm{~mL}$ of electrolyte was used for electrochemical measurements.

\section{Potentiodynamic Polarization}

The polarization curves were recorded by using Solatron Electrochemical analyzer model $(1284 \mathrm{Z})$ interfaced with an IBM computer. Experiments were carried out from $-0.1 \mathrm{~V}$ to $-1 \mathrm{~V}$ potential ranges.

\section{Electrochemical Impedance Spectroscopy (EIS)}

EIS experiments were conducted using Solatron Electrochemical analyzer model (1284 Z) interfaced with an IBM computer and $\mathrm{Z}$ plot and Corrware softwares. The investigation measured the response of the electrochemical system to a.c. excitation with a frequency ranging from $10 \mathrm{KHz}$ to $100 \mathrm{MHz}$ and peak-to-peak a.c. amplitude of $10 \mathrm{mV}$. The percentage inhibition efficiency (IE) was calculated from,

$$
\mathrm{IE}=\frac{\mathrm{R}_{\mathrm{ct} \text { (inhibitoi) }}-\mathrm{R}_{\mathrm{ct}(\text { Blank })}}{\mathrm{R}_{\mathrm{ct} \text { (inhibitoy) }}} \times 100
$$

$\mathrm{R}_{\text {ct (inhibitot) }}$ - Charge transfer resistance in presence of inhibitor.

$\mathrm{R}_{\text {ct(Blank) }}$ - Charge transfer resistance in absence of inhibitor.

\section{Surface Analysis}

The surface analysis of mild steel before and after the immersion in the investigated inhibitor was carried out using optical electron microscope and to observe the presence of plant constituents adsorbed on the metal surface FT-IR spectra was recorded.

\section{Results and Discussion}

\section{Weight Loss Measurements}

\section{Effect of Concentration and Immersion Period}

The corrosion rate for the mild steel coupons in $1 \mathrm{M} \mathrm{HCl}$ solutions containing different concentrations of SFCN extract is presented in Figure 1. It is observed that the corrosion rates decreased with the increase in concentration of SFCN extract. The results obtained are shown in Table 1 and indicate that the plant extract shows a significant inhibitive effect on mild steel in $\mathrm{HCl}$ solutions. From Figure 1, it is observed that the inhibition efficiencies increase with increase in SFCN extract concentration. This indicates that the phytochemical components of the extracts are adsorbed onto the mild steel surface resulting in the blocking of the reaction sites and protection of the mild steel surface from the attack of the corrosion active ions in the acid medium. The values of the percentage inhibition efficiency were determined for various immersion period and the results are tabulated in Table 1. Inspection of the table reveals that the inhibition efficiency of SFCN extract enhanced to $97 \%$ at higher 
concentration. Inhibition efficiency of SFCN extract with immersion time increases up to $3 \mathrm{~h}$ furnishing $93.5 \%$ and inhibition efficiency decreases to $85 \%$ at $6 \mathrm{~h}$ then raise up to $95 \%$ at $12 \mathrm{~h}$ and $97 \%$ at $24 \mathrm{~h}$. As the period of immersion increases, the adsorbed molecules on the surface increases and it was found to be $97.3 \%$ at $0.3 \%$ concentration for $24 \mathrm{~h}$. This enhanced IE with immersion time infers the stability of the adsorbed layer on mild steel surface.

Table 1. Influence of concentration of SFCN extract and time on the corrosion rate of MS in $1 \mathrm{M} \mathrm{HCl}$.

\begin{tabular}{|c|c|c|c|c|c|c|c|c|c|c|c|c|}
\hline \multirow[b]{3}{*}{ Conc. $(\%)$} & \multicolumn{12}{|c|}{ Immersion Time (Hrs) } \\
\hline & \multicolumn{2}{|c|}{$1 / 2$} & \multicolumn{2}{|c|}{1} & \multicolumn{2}{|c|}{3} & \multicolumn{2}{|c|}{6} & \multicolumn{2}{|c|}{12} & \multicolumn{2}{|c|}{24} \\
\hline & $\begin{array}{l}\stackrel{\gtrsim}{\Xi} \\
\dot{\Xi} \\
\dot{u}\end{array}$ & $\begin{array}{l}\partial^{\circ} \\
\dot{\theta}\end{array}$ & 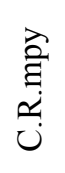 & $\begin{array}{l}\partial^{\circ} \\
\dot{\theta}\end{array}$ & $\begin{array}{l}\text { a } \\
\text { ن. } \\
\text { ن. }\end{array}$ & घิ ฮீ & 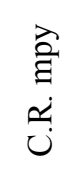 & $\begin{array}{l}\partial 0 \\
\mu\end{array}$ & $\begin{array}{l}\text { ટ્ } \\
\text { : } \\
\text { تُ }\end{array}$ & $\begin{array}{l}\stackrel{0}{ } \\
\stackrel{\theta}{\theta}\end{array}$ & 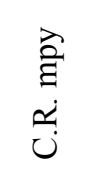 & मீ \\
\hline Blank & 893 & - & 36 & - & 1006 & - & 377 & - & 1531 & - & 1606 & - \\
\hline 0.05 & 307 & 65.6 & 19 & 46.5 & 96 & 90.3 & 61 & 83.7 & 171 & 88.7 & 74 & 95.3 \\
\hline 1 & 256 & 71.3 & 16 & 55.4 & 87 & 91.3 & 60 & 84.1 & 152 & 90.0 & 70 & 95.6 \\
\hline 0.15 & 241 & 72.9 & 15 & 57.5 & 87 & 91.2 & 59 & 84.3 & 115 & 92.4 & 52 & 96.7 \\
\hline 0.2 & 220 & 75.3 & 13 & 62.3 & 76 & 92.4 & 55 & 85.2 & 75 & 95.0 & 49 & 96.9 \\
\hline 0.25 & 196 & 78.0 & 13 & 63.2 & 69 & 93.0 & 55 & 85.2 & 58 & 96.2 & 44 & 97.2 \\
\hline 0.3 & 186 & 79.1 & 12 & 64.2 & 66 & 93.4 & 48 & 87.0 & 52 & 96.6 & 42 & 97.3 \\
\hline 0.35 & 192 & 78.4 & 12 & 66.1 & 59 & 94.1 & 51 & 86.4 & 53 & 96.5 & 47 & 97.0 \\
\hline 0.4 & 192 & 78.4 & 12 & 64.8 & 64 & 93.5 & 52 & 86.2 & 68 & 95.5 & 44 & 97.2 \\
\hline 0.45 & 195 & 78.1 & 12 & 64.8 & 65 & 93.5 & 56 & 85.1 & 70 & 95.3 & 44 & 97.2 \\
\hline
\end{tabular}

\section{Effect of Temperature}

Figure 2 shows the relationship between temperature and the inhibitor efficiency. IE values increase with increase in temperature up to $345 \mathrm{~K}$ at all studied concentration. This indicates that SFCN extract is adsorbed physically at low temperature wile chemisorption is favoured at higher temperatures. The maximum efficiency was observed as $90.9 \%$ at $345 \mathrm{~K}$. Hence the SFCN extract works out as an excellent inhibitor at higher temperatures.

It can also be explained as adsorption and desorption of inhibitor molecules continuously occur at the metal surface and an equilibrium exists between these two processes at a particular temperature. With the increase of temperature, equilibrium between adsorption and desorption processes is shifted leading to a higher desorption rate than adsorption until equilibrium is again established at a different value of equilibrium constant. It explains the lower inhibition efficiency at higher temperature especially at low concentration of the inhibitor. 


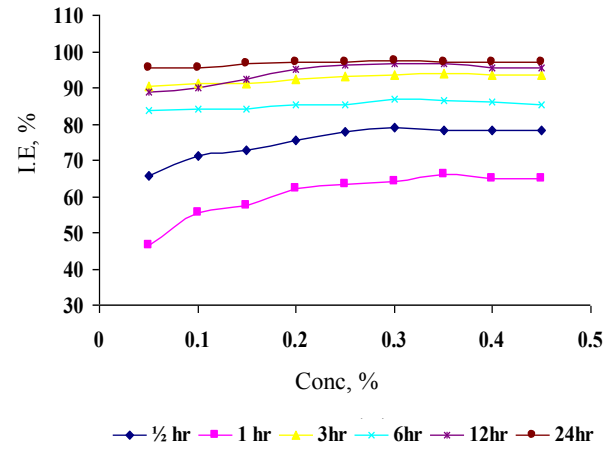

Figure 1. Role of concentration and immersion time on I.E. of SFCN extract.

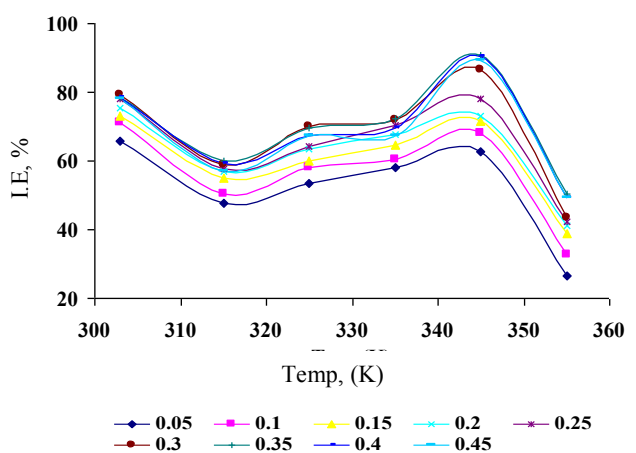

Figure 2. Temperature effect of SFCN extract on I.E.

\section{Adsorption Behavior}

The adsorption behavior of staminate flower extract on mild steel surface was also studied by fitting data obtained for degree of surface coverage to different adsorption isotherms like Langmuir and Temkin, adsorption isotherms. The tests reveal that the adsorption of staminate flower extract on mild steel surface is best described by Langmuir and Temkin adsorption isotherms. The expression for the Langmuir adsorption model can be written as follows:

$$
\log [\theta / 1-\theta]=\log \mathrm{K}+\log \mathrm{C},
$$

where $\mathrm{C}$ is the concentration of the inhibitor in the electrolyte, $\theta$ is the degree of surface coverage of the inhibitor and $\mathrm{K}$ is the adsorption equilibrium constant. Using above equation, the plot of $(\theta / 1-\theta) V s . \log \mathrm{C}$ (Figure 3) was found to be linear, indicating the application of the Langmuir model to the adsorption of Staminate flower extract on mild steel surface. From the results obtained, the correlation values (obtained for lines on the plots) are very close to unity indicating that there is a strong adherence of the inhibitor's adsorption of to the assumptions establishing Langmuir isotherm.

The adsorption of staminate flower extract was also found to be occurred according to Temkin adsorption isotherm. The plots of $\theta$ versus $\log \mathrm{C}$ were also linear, which also indicate the application of the Temkin isotherm to the adsorption of staminate flower extract on mild steel surface.

\section{Activation Energy and Thermodynamic Parameters}

The kinetic parameter of the system under consideration was evaluated using the data obtained from weight loss method for various concentration of the SFCN extract at different temperature. Figure 4 depicts an Arrhenius plot (corrosion rate against the reciprocal of temperature $(1 / T)$ ) for mild steel in $1 \mathrm{M} \mathrm{HCl}$ solution in the absence and presence of different inhibitor concentrations. Satisfactory straight lines of high correlation coefficients were obtained and the activation energy can be obtained from the slopes. The activation energies obtained are listed in Table 2. In the present investigation, Ea for blank $1 \mathrm{M} \mathrm{HCl}$ was found to be $60 \mathrm{KJ} / \mathrm{mol}$ for the corrosion process which lies in the range of the most frequently cited values, the majority of which are grouped around $60.7 \mathrm{KJ} / \mathrm{mol}^{34}$. It is clear that Ea values in the presence of inhibitor are much higher than those in the absence of inhibitor. The higher activation energies mean a slow reaction and that the reaction rate is very sensitive to temperature. The increase in apparent activation energy of mild steel in the presence of staminate flower extract denotes physical adsorption ${ }^{35}$. However the chemical adsorption cannot be excluded at higher temperatures. Similar result has been reported by ${ }^{36}$ on the inhibition of acid corrosion of carbon steel using aqueous extract of olive leaves. 


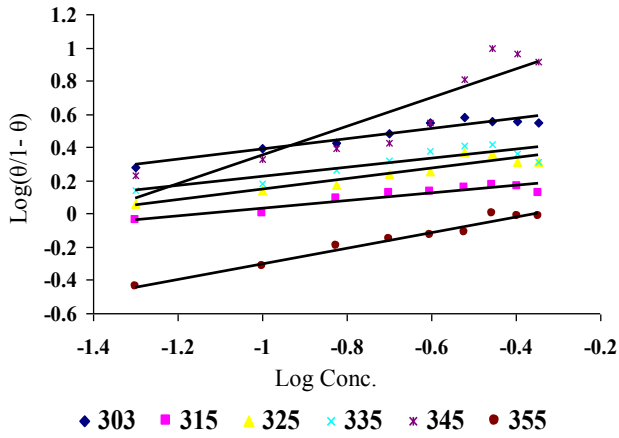

Figure 3. Langmuir adsorption isotherm for SFCN extract.

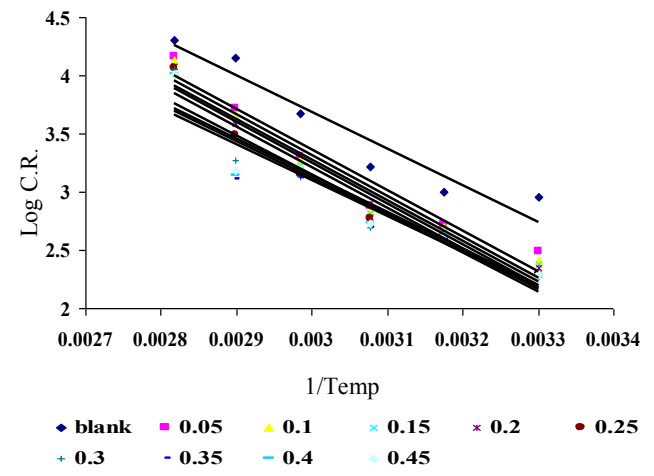

Figure 4. Arrhenius plot of MS in the presence of SFCN extract.

Table 2. Kinetic and thermodynamic parameters during adsorption of inhibitor on MS surface in SFCN extract in $1 \mathrm{M} \mathrm{HCl}$.

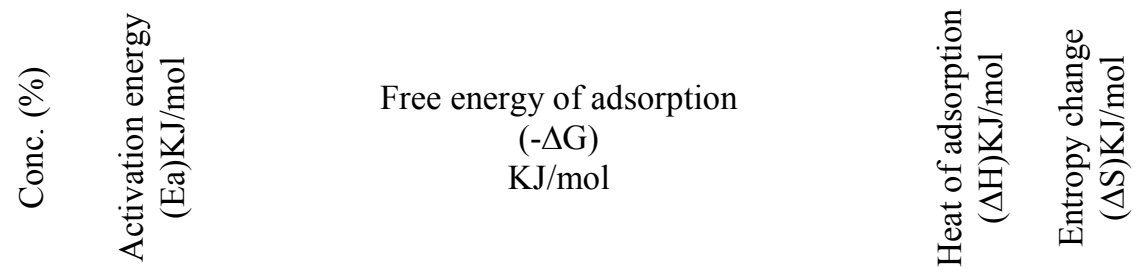

\begin{tabular}{cccccccccc}
\hline \multicolumn{1}{c}{} & & $305 \mathrm{~K}$ & $315 \mathrm{~K}$ & $325 \mathrm{~K}$ & $335 \mathrm{~K}$ & $345 \mathrm{~K}$ & $355 \mathrm{~K}$ & & \\
\hline Blank & 60.08 & - & - & - & - & - & - & - & - \\
\hline 0.05 & 66.67 & 19.26 & 18.08 & 19.28 & 20.42 & 21.59 & 17.67 & -1.46 & 6.53 \\
\hline 1 & 67.33 & 18.18 & 16.55 & 17.94 & 18.76 & 20.27 & 16.49 & -0.86 & 5.91 \\
\hline 0.15 & 66.61 & 17.36 & 16.00 & 17.05 & 18.12 & 19.56 & 16.09 & -2.03 & 6.05 \\
\hline 0.2 & 67.18 & 16.95 & 15.44 & 16.67 & 17.69 & 18.95 & 15.52 & -1.62 & 5.78 \\
\hline 0.25 & 66.84 & 16.77 & 14.94 & 16.15 & 17.42 & 19.10 & 15.02 & -4.53 & 6.59 \\
\hline 0.3 & 63.96 & 16.48 & 14.59 & 16.38 & 17.13 & 20.30 & 14.60 & -13.82 & 9.49 \\
\hline 0.35 & 59.21 & 15.98 & 14.29 & 15.92 & 16.74 & 21.10 & 14.96 & -21.70 & 11.86 \\
\hline 0.4 & 60.02 & 15.65 & 13.86 & 15.26 & 16.03 & 20.49 & 14.46 & -19.59 & 11.04 \\
\hline 0.45 & 60.47 & 15.31 & 13.33 & 14.93 & 15.40 & 19.81 & 14.10 & -17.70 & 10.30 \\
\hline
\end{tabular}

Moreover, the increase in activation energy is proportional to the inhibitor concentration, indicating that the energy barrier for the corrosion process is also increased ${ }^{37}$. The increase in activation energy with inhibitor concentration is often interpreted by physical adsorption with the formation of an adsorptive film of an electrostatic character and chemisorption may occur at higher temperatures. The equilibrium constant of adsorption of staminate flower extract is related to the free energy of adsorption $\Delta \mathrm{G}$ according to the following equation:

$\log C=\log (\theta / 1-\theta)-\log B$,

where $\log \mathrm{B}=-1.74-(-\Delta \mathrm{G} / 2.303 \mathrm{RT}), \mathrm{C}=$ inhibitor concentration. 
The negative values of $\Delta \mathrm{G}$ ensure the spontaneity of the adsorption process and stability of the adsorbed layer on the mild steel surface ${ }^{38}$. Furthermore it is found that $\Delta G$ slightly increases with temperature up to $345 \mathrm{~K}$. The values of $\Delta \mathrm{G}$ increases with increase in temperature indicate that SFCN extract is adsorbed physically at low temperature while chemisorption is favoured at higher temperatures.

The negative values of $\Delta \mathrm{H}$ also show that the adsorption of inhibitor is an exothermic process $^{39}$. Generally an exothermic process signifies either physical or chemisorption while endothermic process is attributable unequivocally to chemisorption ${ }^{40}$. The adsorption of inhibitor molecule is accompanied by positive values of $\Delta \mathrm{S}$. Positive values of $\Delta \mathrm{S}$ show a decrease in the system disorder ${ }^{41}$.

\section{Potentiodynamic Polarization Studies}

The effect of SFCN extract concentration on the anodic and cathodic polarization behavior of mild steel in $1 \mathrm{M} \mathrm{HCl}$ solution has been studied by polarization measurements and the recorded Tafel plots are shown in Figure 5. The respective kinetic parameters derived from the above plots are given in Table 3. It is illustrated from the data of Table 3 that both anodic metal dissolution of iron and cathodic hydrogen evolution reaction were inhibited after the addition of SFCN extract to $1 \mathrm{M} \mathrm{HCl}$ solution. The decrease in $\mathrm{I}_{\text {corr }}$ values infers that the inhibitor in the present investigation is adsorptive type. In the presence of inhibitor there was no significant change in corrosion potential $\left(\mathrm{E}_{\text {corr }}\right)$ which suggests that the inhibitor is mixed type inhibitor by controlling both anodic and cathodic reactions. The inhibition of these reactions was more pronounced on increasing SFCN extract concentration, affording a maximum of $75 \%$ IE. Values of $b_{a}$ and $b_{c}$ do not follow any possible trend, suggesting that SFCN extract acts as mixed-type inhibitor. Linear polarization resistance Rp of mild steel in $\mathrm{HCl}$ increases with increase in concentration of SFCN extract which indicates the inhibition process is mainly due to adsorption of SFCN extract on mild steel surface. $62 \%$ IE was observed at maximum concentration of SFCN extract.

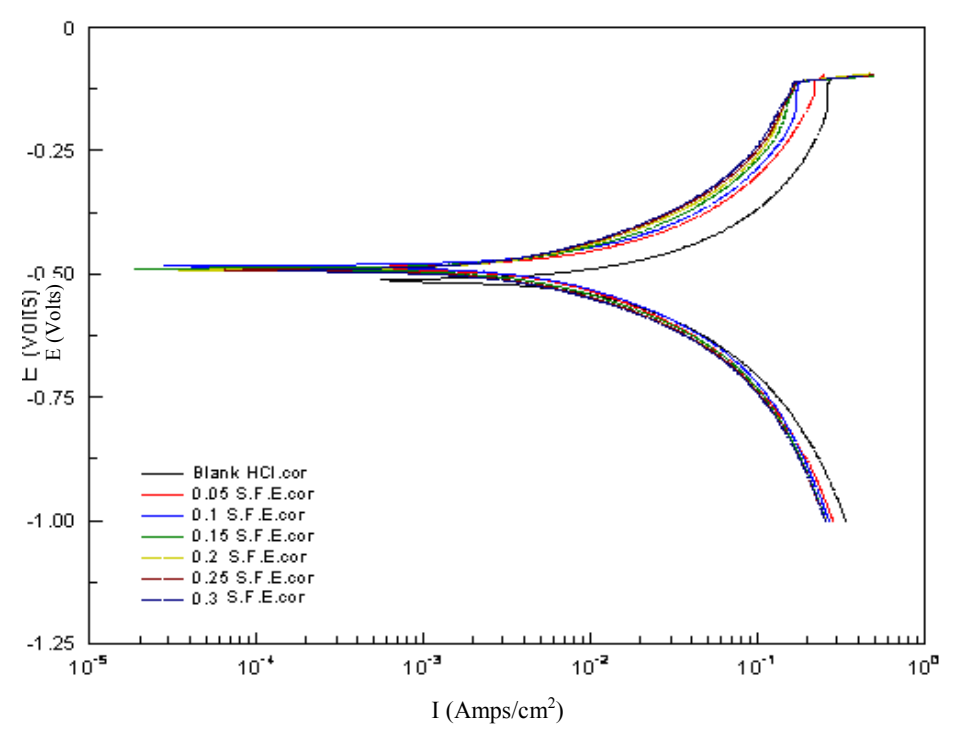

Figure 5. Polarization curves of MS in the presence of SFCN extract in acid medium. 
Table 3. Electrochemical data by Linear and Tafel polarization for corrosion of MS in the presence of SFCN extract in $\mathrm{HCl}$.

\begin{tabular}{cccccccc}
\hline $\begin{array}{c}\text { Conc. of } \\
\text { S.F.E, } \%\end{array}$ & $\begin{array}{c}\text {-Ecorr } \\
\times\left(10^{-3}\right) \\
(\text { Volts })\end{array}$ & $\begin{array}{c}\text { Icorr } \\
\times\left(10^{-4}\right) \\
\left(\mathrm{Amp} / \mathrm{cm}^{2}\right)\end{array}$ & $\begin{array}{c}\mathrm{ba} \\
(\mathrm{mV} / \mathrm{dec})\end{array}$ & $\begin{array}{c}\mathrm{bc} \\
(\mathrm{mV} / \mathrm{dec})\end{array}$ & $\begin{array}{c}\mathrm{IE}, \\
\%\end{array}$ & $\begin{array}{c}\mathrm{Rp} \\
\mathrm{Ohm} / \mathrm{cm}^{2}\end{array}$ & $\begin{array}{c}\mathrm{IE}, \\
\%\end{array}$ \\
\hline Blank & 513 & 184.45 & 254.64 & 183.16 & - & 2.55 & - \\
0.05 & 487 & 95.747 & 219.55 & 155.9 & 48.0 & 4.13 & 38.1 \\
0.1 & 484 & 69.924 & 169.16 & 141.45 & 62.0 & 4.58 & 44.2 \\
0.15 & 489 & 64.51 & 169.03 & 149.3 & 65.0 & 5.56 & 54.0 \\
0.2 & 491 & 53.812 & 154.42 & 154.79 & 70.8 & 6.23 & 59.0 \\
0.25 & 492 & 49.392 & 150.08 & 152.91 & 73.2 & 6.45 & 60.3 \\
0.3 & 492 & 45.988 & 141.69 & 138.34 & 75.0 & 6.80 & 62.4 \\
\hline
\end{tabular}

\section{Electrochemical Impedance Spectroscopy}

Impedance diagram (Nyquist plot) obtained for mild steel in $1 \mathrm{M} \mathrm{HCl}$ in the presence of various concentrations of the inhibitor is depicted in Figure 6. They are not perfect semicircles and this was attributed to charge transfer reaction. Impedance parameters derived from Nyquist plots are tabulated in Table 4.

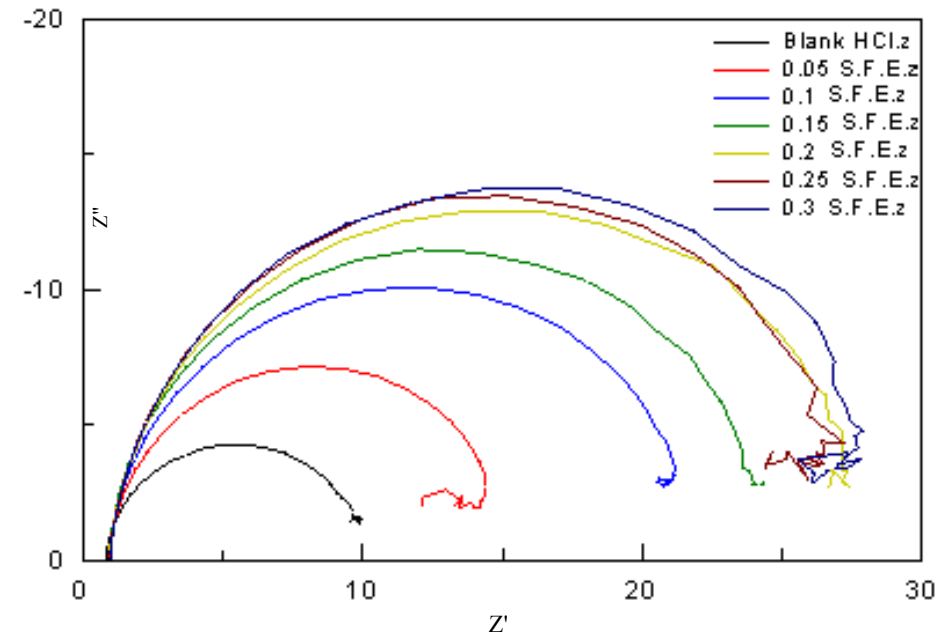

Figure 6. Impedance behavior of MS in the presence of SFCN extract Nyquist Plot.

Table 4. Impedance parameters of MS in the presence of SFCN extract in $\mathrm{HCl}$.

\begin{tabular}{ccccc}
\hline $\begin{array}{c}\text { Conc. of S.F.E, } \\
\%\end{array}$ & $\mathrm{R}_{\mathrm{ct}} \Omega \mathrm{cm}^{2}$ & $\mathrm{IE}, \%$ & $\mathrm{C}_{\mathrm{dl}} \times 10^{-5} \mu \mathrm{F}$ & $\theta$ \\
\hline Blank & 9.2 & - & 60.1 & - \\
0.05 & 13.5 & 31.6 & 39.5 & 0.34 \\
0.1 & 20.9 & 55.8 & 38.1 & 0.36 \\
0.15 & 23.4 & 60.4 & 35.4 & 0.41 \\
0.2 & 27.1 & 65.8 & 34.4 & 0.42 \\
0.25 & 27.4 & 66.2 & 29.0 & 0.51 \\
0.3 & 28.7 & 67.7 & 28.4 & 0.52 \\
\hline
\end{tabular}


It can be seen that as the concentration of inhibitor increases Rct value increases but, $\mathrm{Cdl}$ values decreases. Decrease in $\mathrm{Cdl}$, which can result from an increase in thickness of electrical double layer, suggests that the inhibitor molecules function by adsorption at the metal- solution interface. Maximum concentration of the studied inhibitor furnished around $68 \%$ IE.

\section{Comparison of Electrochemical Techniques with the Conventional Weight Loss Method}

In the current investigation on inhibitive properties of SFCN extract on mild steel acid corrosion by various techniques conducted infer that IE obtained by weight loss method are different from IE obtained using electrochemical techniques (Figure 7). The difference observed can be attributed to the fact that weight loss methods give average corrosion rates where as electrochemical methods give instantaneous corrosion rates. This difference may also expected to arise because of the difference in the time required to form an adsorbed layer of the plant extract which can bring down corrosion ${ }^{42}$.

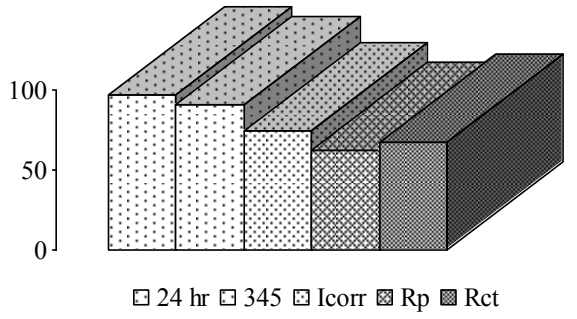

Figure 7. Comparison of IE between weight loss method and electrochemical measurements for SFCN extract.

\section{Shelf Life of the Extract}

Natural inhibitors are estimated by their stability, consistent performance, and biodegradability. To test the consistent performance of the extracts under study, weight loss experiments were conducted for a period of 3months. The extract was stored at room temperature and in refrigerator. The results are presented in the Table 5.

Table 5. Shelf life of SFCN extract.

\begin{tabular}{ccc}
\hline Period of & \multicolumn{2}{c}{ IE \% } \\
\cline { 2 - 3 } study (weeks) & R.T. & R.C. \\
\hline 1 & 96.4 & 90.9 \\
2 & 92.8 & 89.1 \\
3 & 91.9 & 88.8 \\
4 & 86.6 & 87.4 \\
5 & 85.8 & 87.0 \\
6 & 84.1 & 84.2 \\
7 & 83.2 & 82.2 \\
8 & 82.9 & 79.0 \\
9 & 79.5 & 75.5 \\
10 & 77.8 & 72.6 \\
\hline
\end{tabular}


The data in table revealed that the inhibition efficiency slowly decreased during storage. This may be due to some chemical reactions between the constituents. Due to the reactions the active groups responsible for the adsorption on the MS surface may not be available for adsorption. Therefore the total surface covered decreased showing decline of inhibition efficiency. $75 \%$ of inhibition efficiency after 3 months is appreciable. This confirms that they can be stored at room temperature itself.

\section{Optical Electron Microscope}

Optical electron microscope images were indicative of the changes that accompany the corrosion and protection on the MS surface of the mild steel. Figure 8a showed an overall attack up to 80 percent of MS surface which was reduced to about 10 to 20 percent by the addition of inhibitor (Figure $8 \mathrm{~b}$ ).

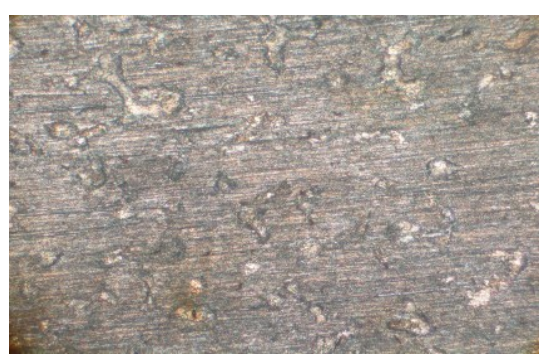

Figure $8 \mathrm{a}$

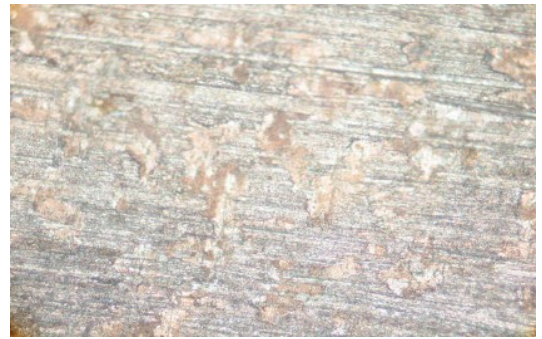

Figure $8 \mathrm{~b}$

Figure 8. Photomicrograph of MS in presence of $\mathrm{HCl}(8 \mathrm{a}) \&$ in presence of SFCN extract (8b).

\section{FT-IR Technique}

\section{Staminate Flower Extract}

Characteristic IR absorption spectra of SFCN extract concentrate and the adsorbed material were taken. The broad absorption bands at $3750-3200 \mathrm{~cm}^{-1}$ and at $1022 \mathrm{~cm}^{-1}$ in the extract spectrum confirms the presence of $-\mathrm{OH}$ group. The presence of primary amine is indicated by the absorption peak at $1629.74 \mathrm{~cm}^{-1}$. The IR absorption spectra of the adsorbed material revealed that the adsorbed material is not IR active. Frequencies of adsorption of $-\mathrm{OH}$ and amino groups were missing. This suggests that the adsorption of the inhibitor on the surface of mild steel might have occurred through the missing bonds ${ }^{43}$.

\section{Mechanism}

The SFCN extract contain number of oxygen containing organic compounds. Adsorption of these compounds may occur through their active centre. The Langmuir and Temkin adsorption isotherm also support the adsorption phenomenon. These isotherms could infer that the plant extract such as staminate flower are found to be adsorbed on the MS surface and it could form a monolayer of adsorption. 


\section{Mechanism of Inhibition by Staminate Flower Extract}

Skeletal representation of the inhibition process.

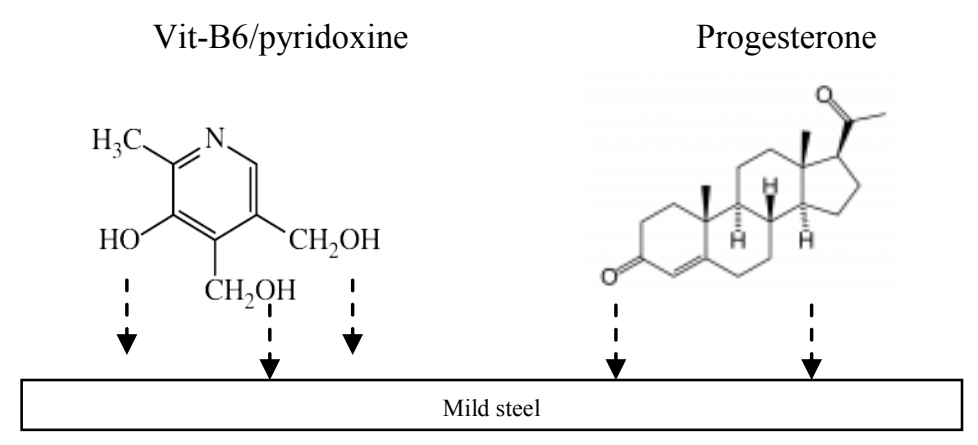

These constituents of the extract are mostly composed of oxygen and nitrogen containing compounds. Adsorption of these compounds may also form complexes with metallic cations. In the present case the oxygen containing constituents of the extract and hydroxy aromatic compounds can form a complex layer on the metal surface.

The extract in $\mathrm{HCl}$ medium is believed to interact physically and chemically with the metal surface forming a protective layer and hence can retard the dissolution of the metal. Similar findings are furnished $\mathrm{in}^{44}$. The presence of cations such as $\mathrm{Na}, \mathrm{NH}_{4}, \mathrm{Mg}, \mathrm{Ca}, \mathrm{Zn}$, etc. and anions such as $\mathrm{Cl}^{-}$, phosphate, and sulphate might influence the inhibition through synergism. Thus, the extract of staminate flower is found to be promising inhibitor to retard the corrosion of MS in acid medium.

\section{Conclusion}

From the experimental part carried out it was found that the maximum efficiency of SFCN extract was found to be $97.3 \%$ at $24 \mathrm{~h}$ of immersion and the extract under study resist corrosion at higher temperature, the optimum temperature being $345 \mathrm{~K}$. The adsorption behavior of the inhibitor is consistent with Langmuir and Temkin adsorption models. The thermodynamics/kinetics parameters obtained indicate that the adsorption of SFCN extract onto the mild steel surface is spontaneous, exothermic, and increase the entropy order. Activation energies were higher in the presence of the SFCN extract suggesting the physiosorption mechanism at low temperature and chemisorption at higher temperatures. The Ecorr values and values of Tafel slopes $b_{a}$ and $b_{c}$ obtained from Tafel intercept method would confirm the inhibition of corrosion of MS is under mixed control. The increase in Rct values and decrease in $\mathrm{Cdl}$ values confirm the formation of an insulated protective layer over the mild steel surface. Results obtained for the durability test infer the strong inhibitive action of the inhibitor kept at room temperature as well as in the refrigerator for 3 months. Examination of the surface of the metal in the presence of the inhibitors confirmed the deposition of inhibitor on the metal surface. Hence it can be concluded that staminate flower being a natural and environmentally benign product can be used instead of toxic chemical inhibitors in preventing MS from corrosion. 


\section{References}

1. Oguzie E.E, Corros Sci., 2008, 50, 2993.

2. Umoren S.A and Ebenso E.E, Pigment Resin Technol., 2008, 37, 173.

3. Umoren S.A and Obot I.B, Surf Rev Lett., 2008, 15, 277.

4. $\quad$ El -Etre A Y, Appl Surf Sci., 2006, 252, 8521.

5. Zucchi F and Omar I.H, Surf Technol., 1985, 24, 391.

6. Oguzie E.E, Mater Chem Phys., 2006, 99, 441.

7. Oguzie E.E, Pigment Resin Technol., 2005, 34, 321.

8. Oguzie E.E, Mater Chem Phys., 2006, 213, 441.

9. Chaieb E, Bouyanzer A, Hammouti B and Berrabah M, Acta Phys Chim Sin., 2009, 25, 1254 .

10. Sharma M K, Arora P, Kumar S, Mathur S P and Ratnani R, Corros Eng Sci Technol., 2008, 43, 213.

11. El-Etre A.Y, Mater Chem Phys., 2008, 108, 278.

12. El-Etre A.Y, J Coll Interf Sci., 2007, 314, 578.

13. Raja P B and Sethuraman M G, Surf Rev Lett., 2007, 14, 1157.

14. Abiola O K, Otaigbe J O E and Kio O.J, Corros Sci., 2009, 51, 1879.

15. Jain T, Chowdhary R and Mathur S P, Mater Corrosion, 2006, 57, 422.

16. Sethuraman M G and Raja P B, Pigment Resin Technol., 2005, 48, 2765.

17. Okafor P C, Ekpe U J, Ebenso E.E, Umoren E M and Leizou K E, Bull Electrochem., 2005, 21, 347.

18. Gunasekaran G and Chauhan L R, Electrochim Acta., 2004, 49, 4387.

19. Loto C A, Mohammed A I and Loto R O, Corrosion Preven Control, 2003, 50, 107.

20. Abiola O K and Otaigbe J O E, Corros Sci., 2009, 51, 2790.

21. Rajalakshmi R, Subhashini S, Leelavathi S and Femina Mary R, Oriental J Chem., 2008, 24 (3) 1085- 1090.

22. Rajalakshmi R, Subhashini S, Nanthini M and Srimathi M, Oriental J Chem., 2009, 25 (2) 313-318.

23. Rajalakshmi R, Subhashini S and Prithiba A, Asian J Chem.., 2010, 22

24. Rajalakshmi R, Subhashini S, Leelavathi S and Geethanjali R, J Nepal Cheml Soc, 2010, 25,29-36.

25. Subhashini S, Rajalakshmi R, Elakkiya T and Srimathi M, J Ultra Chem., 2008, 4(2) 159-164.

26. Subhashini S, Rajalakshmi R, Kowshalya V N, Materi Sci Res India, 2008, 5(2) 423-428.

27. Subhashini S, Rajalakshmi R and Safina A S, Mater Sci Res India, 2008, 5(2) 375-382.

28. Subhashini S, Rajalakshmi R, Prithiba A and Mathina A, E-J Chem., 2010, 7(4), 1133- 1137.

29. Karthikaiselvi R, Subhashini S and Rajalakshmi R, J Corros Sci Eng., Vol 12 pre print 33.

30. Vijayalakshmi P R, Rajalakshmi R and Subhashini S, Asian J Chem., 2010, 22, 45374548.

31. Vijayalakshmi P R, Rajalakshmi R and Subhashini S, E-J Chem., 2010, 7(3), 1055 - 1065.

32. Vijayalakshmi P R, Rajalakshmi R and Subhashini S, Portugaliae Electrochimica Acta, 2011, 29(1), 9-21.

33. Vijayam, Ravi, Deepti, Vimal, Dalvi, Maithali; A process to apply the effectiveness of Coconut Flower; 2004.

34. Riggs O.L and Hurd R M, Corrosion, 1967, 23, 252.

35. Popova A, Sokolova E, Raicheva S and Christov M, Corros Sci., 2003, 45,33.

36. El-Etre A.Y, J Colloid Interface Sci., 2007, 314, 578.

37. Zucchi F, Trabanelli G and Brunoro G, Corros Sci., 1994, 36, 1683. 
1644 R. RAJALAKSHMI et al.

38. Ali S.A, El-shareef A M and Al-ghamdi R F, Saeed M T, Corros Sci., 2005, 47, 2659.

39. Gomma G.K and Wahdan M H, Mater Chem Phys., 1995, 39,211.

40. Durnie W, De Marco R, Kinsella B and Jefferson A, J Electrochem Soc., 1999, 146, 1751.

41. El Etre A Y, Corros Sci., 2006, 45,316.

42. Muralidharan S, Quraishi M A and Iyer S V K, Corros Sci., 47(11), 1739-1750

43. Ebenso E E, Eddy N O and Odionegeny A O, Afr J Pure Appl Chem., 2008, 2(11), 107-115.

44. Pravin Kar, Ayman Husein, George Varkey and Gurmeet Singh, Transactions of the SAEST; 1993, 28, 1. 


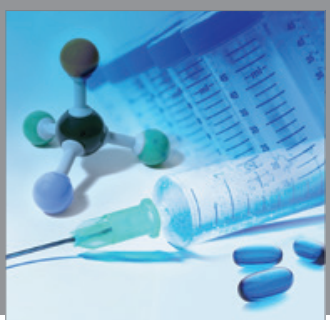

International Journal of

Medicinal Chemistry

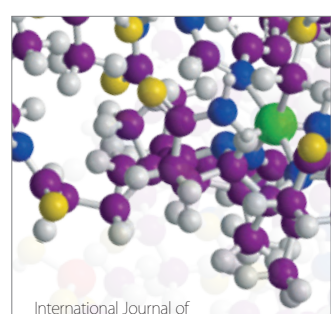

Carbohydrate Chemistry

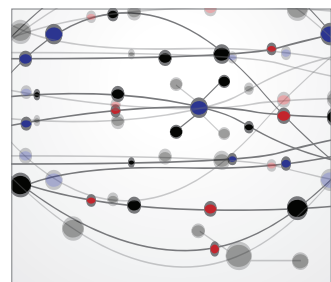

The Scientific World Journal
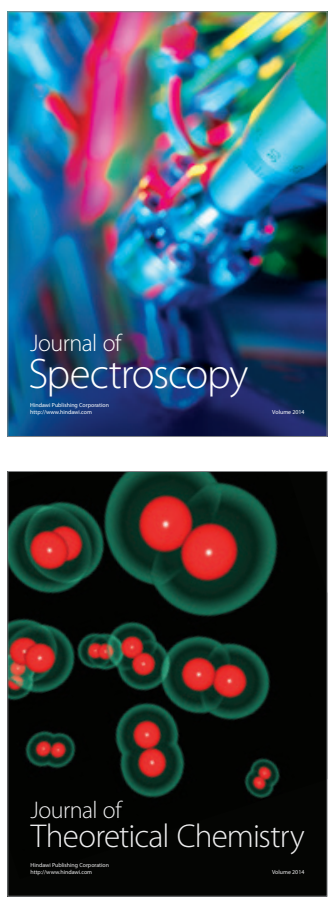
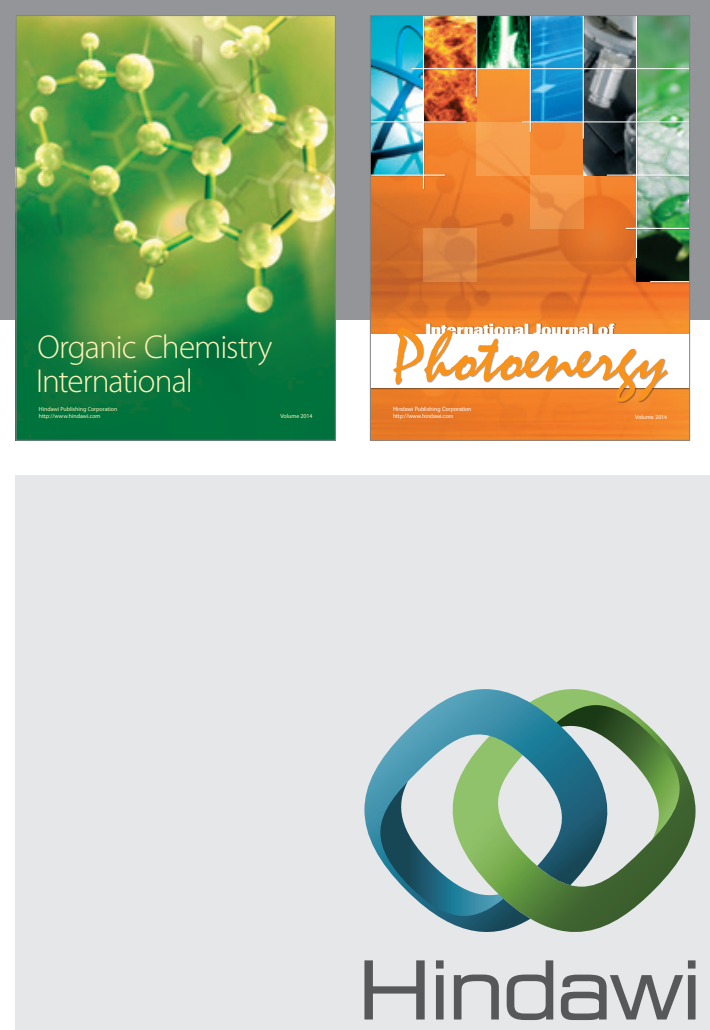

Submit your manuscripts at

http://www.hindawi.com
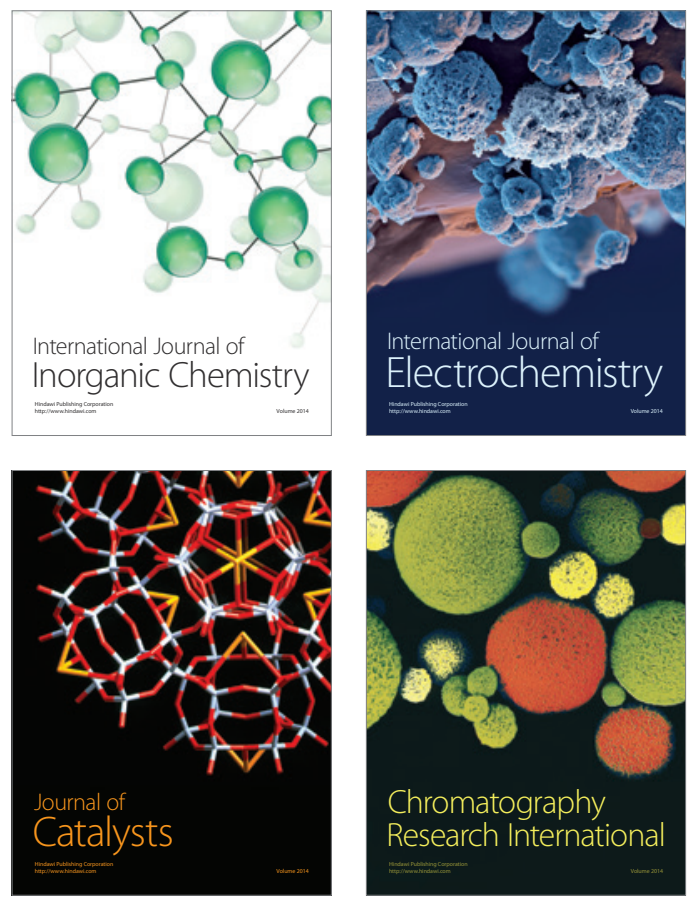
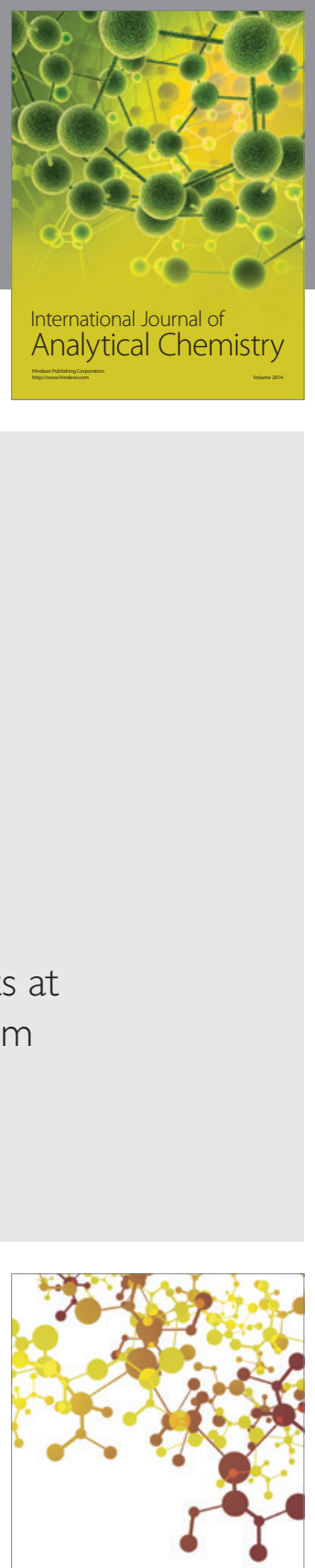

Journal of

Applied Chemistry
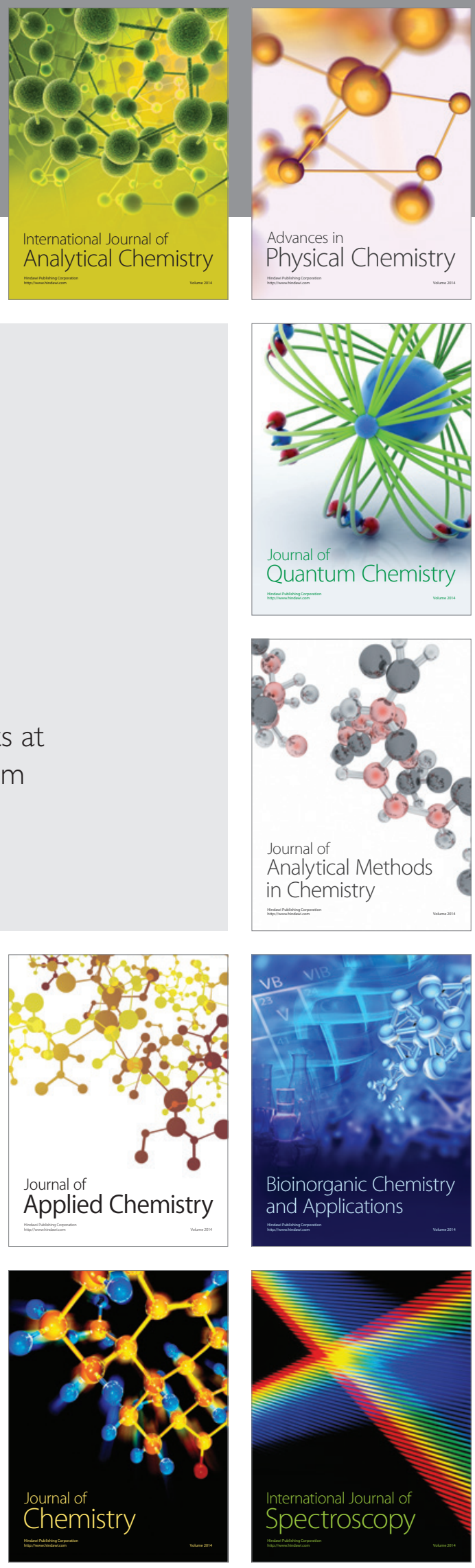